\title{
Preparation of mucosal nanoparticles and polymer-based inactivated vaccine for Newcastle disease and H9N2 AI viruses
}

\author{
Heba M. El Naggar ${ }^{1}$, Mohamed Sayed Madkour ${ }^{1}$ and Hussein Ali Hussein ${ }^{2}$
}

1. Department of Poultry Vaccines Production Unit Veterinary Serum and Vaccine Research Institute, Abbasia 11759, Egypt; 2. Department of Virology, Faculty of Veterinary Medicine, Cairo University, Giza 12211, Egypt.

Corresponding author: Hussein Ali Hussein: husvirol@cu.edu.eg,

Co-authors: HME:elnaggarvet@gmail.com, MSM: madkourmohamed@yahoo.com

Received: 22-08-2016, Accepted: 10-01-2017, Published online: 14-02-2017

doi: 10.14202/vetworld.2017.187-193 How to cite this article: El Naggar HM, Madkour MS, Hussein HA (2017) Preparation of mucosal nanoparticles and polymer-based inactivated vaccine for Newcastle disease and H9N2 AI viruses, Veterinary World, 10(2): 187-193.

\begin{abstract}
Aim: To develop a mucosal inactivated vaccines for Newcastle disease (ND) and H9N2 viruses to protect against these viruses at sites of infections through mucosal immunity.

Materials and Methods: In this study, we prepared two new formulations for mucosal bivalent inactivated vaccine formulations for Newcastle and Avian Influenza (H9N2) based on the use of nanoparticles and polymer adjuvants. The prepared vaccines were delivered via intranasal and spray routes of administration in specific pathogen-free chickens. Cell-mediated and humoral immune response was measured as well as challenge trial was carried out. In addition, ISA71 water in oil was also evaluated.

Results: Our results showed that the use of spray route as vaccination delivery method of polymer and nanoparticles Montanide ${ }^{\mathrm{TM}}$ adjuvants revealed that it enhanced the cell mediated immune response as indicated by phagocytic activity, gamma interferon and interleukin 6 responses and induced protection against challenge with Newcastle and Avian Influenza (H9N2) viruses.
\end{abstract}

Conclusion: The results of this study demonstrate the potentiality of polymer compared to nanoparticles adjuvantes when used via spray route. Mass application of such vaccines will add value to improve the vaccination strategies against ND virus and Avian influenza viruses.

Keywords: adjuvant, H9N2, mucosal, nanoparticles, Newcastle, polymer.

\section{Introduction}

Avian influenza virus (AIV) subtype H9N2 is low pathogenic avian influenza virus and it causes serious economic losses in poultry industry. The H9N2 subtype outbreaks occurred in Germany during 1995 and 1998 in ducks and turkey, Italy in 1994 and 1996 detected in chickens, Ireland in 1997 also isolates from pheasant, ostriches in South Africa in 1995, turkeys in the USA between 1995, and 1996 and finally in chickens flocks in Korea 1996 [1-3].

In 1997, H9N2 virus outbreaks distributed in Asian countries such as Saudi Arabia, Iran, China, Pakistan, and other countries [4].

In Egypt [5], the presence of H6 and H9 AI antibodies $(\mathrm{Ab})$ among broiler and layer breeders flocks were detected using serological tests such as ELISA and hemagglutination inhibition (HI) tests. In 2003, the H9N2 samples have been collected from live bird markets then characterized in the USA by the help of NAMRU [6]. The first publication for isolation of

Copyright: Naggar, et al. Open Access. This article is distributed under the terms of the Creative Commons Attribution 4.0 International License (http://creativecommons.org/licenses/by/4.0/), which permits unrestricted use, distribution, and reproduction in any medium, provided you give appropriate credit to the original author(s) and the source, provide a link to the Creative Commons license, and indicate if changes were made. The Creative Commons Public Domain Dedication waiver (http://creativecommons.org/ publicdomain/zero/1.0/) applies to the data made available in this article, unless otherwise stated.
H9N2 from Egypt was at 2011 which isolated from commercial bobwhite quail [7]. The hemagglutinin gene sequence of the isolated Egyptian viruses showed the highest similarity with one of the recent Israeli strains (97\%) detected from 2006 to 2010 [6]. Now H9N2 subtype AIVs vaccination has been used to face the field outbreaks [8].

Newcastle disease virus (NDV) is one of the most devastating diseases of the poultry industry which shows genetic diversity and complexity [9]. NDV was discovered in 1926 and since that time the NDV was classified to be one serotype and to date can be divided into Class I ( 9 genotypes) and Class II (15 genotype). The new virulent genotypes were observed through the detection of the genomic sequence changes of NDV of low and high virulence at different geographic locations across the world [10-12]. Velogenic NDV caused economic losses among commercial chicken in Egypt [13]. Researchers in vaccines production gave more concerns to develop vaccines that induce protective immunity to prevent and control the virus evolution in poultry flocks [14]. The antigenic diversity of the NDVs isolated from 52 breeders and broiler flocks in Egypt [15], and the genetic resistance of the NDVs in the Egyptian native breeds has been reported [16]. The virulence determined using sequence gene analysis was carried out for local velogenic isolate SR/76 [17]. NDV genotype VII 
was isolated from H5N1 infected broiler flock 2012, this isolate was closely related to Chinese strains so this study reports the characterization of NDV genotype VII in broiler chicken with co-infection with Avian influenza H5N1 virus [18]. The Chinese VII d virus with sever outbreaks of ND was characterized by Radwan et al. [13].

The delivery of inactivated antigens by injection may enhance the humeral immune response but rarely induce mucosal immune response. In the other side, the mucosal antigen delivery can enhance both local and systemic immune responses, which provides an advantageous approach for immunization [19]. The delivery of inactivated influenza virus was tested in mice and resulted in protection against different viruses [20-24]. Mucosal vaccination strategy could be rapid and preventive method of vaccination in outbreaks in endemic areas and it should be suitable for mass application even applied by spray or aerosole and effective after single application [25-29]. In normal circumstances, the inhaled antigen do not trigger strong immune responses through contacting with the respiratory tract mucosa but induce a state of tolerance $[30,31]$ leading to a tolerogenic environment in the mucosa. The applied whole inactivated virus by intranasal route alone is poorly immunogenic [31-33]. To enhance the immunogenicity of whole inactivated virus, it needs to be adjuvanted either with Montanide ${ }^{\mathrm{TM}}$ Gel 01 ST (Gel 01) which is a polymer based adjuvant (gel particles of sodium polyacrylate in water) or Montanide ${ }^{\mathrm{TM}}$ IMS $1313 \mathrm{~N}$ VG (IMS $1313 \mathrm{~N}$ ) (nanoparticles in an aqueous phase containing an immunostimulating compound). Both are suitable for mass vaccination that can be used in intensive poultry industry via spray, shower or drinking water [34-36]. In this study, we prepared two inactivated vaccines based on the use of such adjuvants, and comparative study of the immune response as well as challenge trial was carried out.

\section{Materials and Methods}

Ethical approval

All applicable institutional guidelines for the care and use of animals were followed.

\section{Antigen}

Egyptian two local isolates including influenza A virus (A/chicken/Egypt/114922v/2011(H9N2), and NDV (NDV-B7-RLQP-CH-EG-12) virulent were kindly provided by National Laboratory for Veterinary Control on Poultry Production, Animal Health Research Institute, Egypt. Sequences of these viruses have been found in gene bank under the following accession numbers: for AIV (JQ419502) (sequence of HA gene) and for NDV (112RKQKR*F117KM288609) (sequence of $\mathrm{F}$ gene).

\section{Adjuvants}

Montanide $^{\text {TM }}$ IMS 1313 N VG (IMS 1313 N) and Montanide ${ }^{\mathrm{TM}}$ Gel 01 (Gel 01) and as well as
Montanide $^{\mathrm{TM}}$ ISA $71 \mathrm{VG}$ were used in this study. Montanide ${ }^{\text {TM }}$ IMS is ready to dilute range of adjuvants consisting of liquid particles $(10-500 \mathrm{~nm})$ dispersed in an aqueous phase containing an immunostimulating compound. Montanide ${ }^{\mathrm{TM}} \mathrm{Gel} 01$ is ready to dilute polymeric adjuvant. It contains gel particles of sodium polyacrylate in water. Montanide ${ }^{\mathrm{TM}}$ ISA 71 VG It is a mineral oil based adjuvant that has been developed for manufacture of water-in-oil (W/O) emulsion. The three adjuvants were kindly provided by SEPPIC Co.

\section{Vaccine formulation}

IMS $1313 \mathrm{~N}$ nanoparticles adjuvant was used in ratio (weight) $50 \%$ in aqouse phase; whereas Gel 01 Polymer adjuvant was used in a ratio $10 \%$ with formulation process recommended by manufacture. W/O emulsion vaccine using Montanide ${ }^{\mathrm{TM}}$ ISA $71 \mathrm{VG}$ at a ratio of 30/70 (v/v) aqueous/oil ratio was also prepared. Stable preparations are obtained by mixing the aqueous medium into the Montanide ${ }^{\mathrm{TM}}$ ISA $71 \mathrm{VG}$, at room temperature or less, under vigorous stirring (for $15-30 \mathrm{~min}$ ) as recommended by manufacture the antigen content in all the prepared vaccines not $<10^{8.5}$ embryo infective dose $50 \%\left(\mathrm{EID}_{50}\right)$.

\section{Challenge trial}

About 300 specific pathogen-free 10 days old chickens are divided into six groups (50 chickens each), Groups 1 and 2 were vaccinated with bivalent NDV and H9N2 inactivated vaccine adjuvanted with IMS1313. The vaccine was delivered by intranasal route in Group 1 (each animal received 1 antigen dose in $0.1 \mathrm{ml}$ injected evenly in both nostrils) and spray route in Group 2 (2.5 ml of solution containing 10 doses of vaccine were sprayed over 10 birds in a box). Groups 3 and 4 were vaccinated in dose similar to Groups 1 and 2 with bivalent NDV and H9N2 inactivated vaccine adjuvanted with GEL 01. Group 3 vaccinated by intranasal and group 4 by spray routes. Group 5 was injected I/M with $0.5 \mathrm{ml}$ of inactivated bivalent NDV and $\mathrm{H} 9$ adjuvanted with Montanide ISA 71, and finally, Group 6 were kept non-vaccinated chickens as control negative group. After 3 weeks, postvaccination 10 birds from each of Groups 1 to 5 were challenged with $10^{6} \mathrm{EID}_{50} \mathrm{NDV}$ via ocular rout and another 10 birds from each group were challenged with $10^{6}$ EID50 H9N2 virus also, 20 birds from Group 6 were challenged in separate isolates with NDV and H9N2 (10 birds each) and kept as positive control for the challenged viruses.

Heparinized blood samples from chicken in the six groups at the $1^{\text {st }}, 3^{\text {rd }}, 5^{\text {th }}, 7^{\text {th }}, 10^{\text {th }}, 15^{\text {th }}$ and $21^{\text {th }}$ day postvaccination for identification of interleukin 6 (IL6), interferon gamma (IFN $\gamma$ ) genes by real-time polymerase chain reaction (PCR) and measurement of phagocytic index. Serum samples were collected weekly till 15 weeks postvaccination for detection of serum Abs by HI test. Tracheal swabs from groups that challenged with H9N2 virus were collected and tested for virus shedding by real-time PCR. 


\section{Results}

\section{IFN y response of vaccinated chickens}

Results of quantitative reverse transcription (qRTPCR) assay to measure the IFN $\gamma$ response of vaccinated chicken groups showed variability. Comparing routes of administration of the IMS1313, intranasal route induced response at 7 and 21 , whereas spray route induced high response at 7,15 and 21 days postvaccination. On the other hand, chicken group received Gel 01 via intranasal showed highest response only at $7^{\text {th }}$ compared to those administrated via spray which has response at $15^{\text {th }}$ day postvaccination (Figure-1).

\section{IL6 response of vaccinated chickens}

IL6 response of vaccinated groups of chicks at interval days as measured by qRT-PCR assay showed waves of increasing and decreasing values differ from group to group as shown in Figure-2. Groups 2 and 4 showed discrepancies in the IL6 response with the highest response at $21^{\text {st }}$ days in Group 4. IL6 response in Groups 1 and 3 was low and insignificant. Chicken received Gel 01 via spray was the highest in their IL6 response. On the other hand, the chickens received the ISA71 showed gradual IL6 response at $3^{\text {rd }}, 5^{\text {th }}$, $10^{\text {th }}$ day and reached the highest response at 15 days postvaccination (Figure-2).

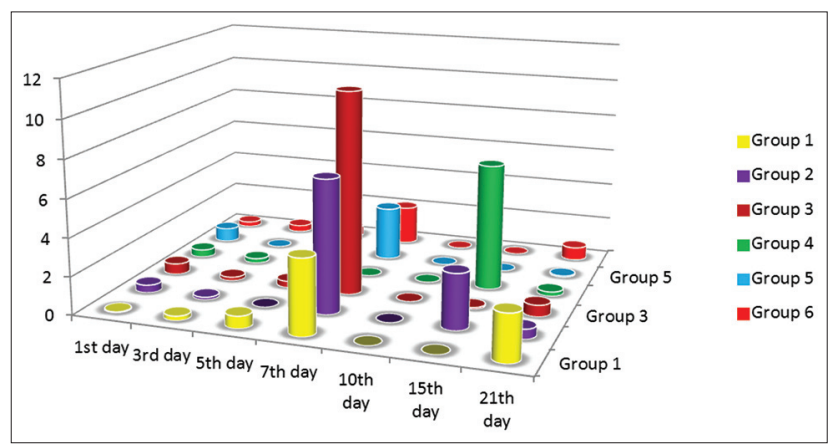

Figure-1: Interferon gamma response in chicken vaccinated with the prepared bivalent Newcastle disease virus and Avian influenza virus H9N2 at interval days postvaccination as measured by quantitative real-time reverse transcription - polymerase chain reaction assay.

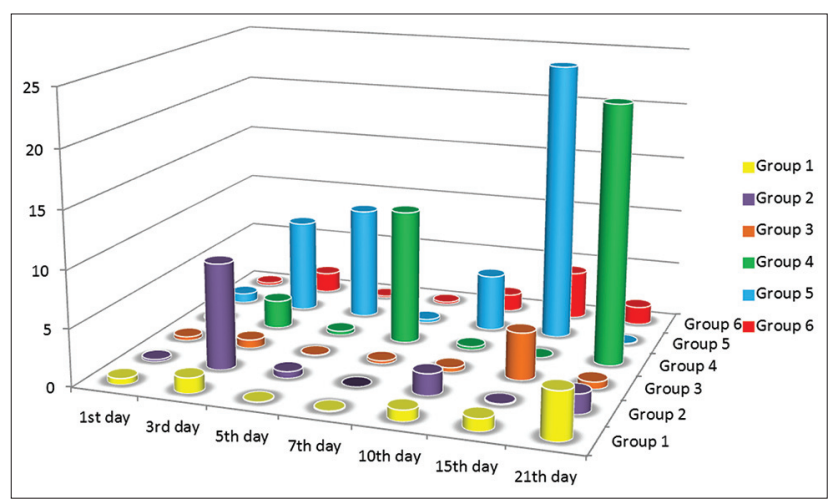

Figure-2: Interleukin 6 response in chicken vaccinated with the prepared bivalent Newcastle disease virus and Avian influenza virus H9N2 at interval days postvaccination as measured by quantitative real-time reverse transcription - polymerase chain reaction assay.

\section{Phagocytic activities}

Phagocytic percentage and index measured at interval day's postvaccination by equations:

Phagocytic percentage $=$ (Number of phagocytes which ingest Candida $/($ total numberofphagocytes $) \times 100$

Phagocytic index $=($ Total numebr of phagocytes which ingest more than two Candida)/(total number of phagocytes which ingest Candida)

The results showed gradual enhancement and the highest activity was in the $7^{\text {th }}$ and $21^{\text {th }}$ day for all groups except Group 1 where increase in activity was at the $15^{\text {th }}$ day and $21^{\text {th }}$ (Figure-3).

\section{Serological response}

Serological response for H9N2 and NDV of vaccinated chicken was monitored by HI test for 15 weeks. H9N2 Abs were detected in a low titer which was not increased above $5 \log 2$ in vaccinated Groups 1-4, Group 5 has a higher titer which reached to $9 \log 2$ at the $7^{\text {th }}$ till $15^{\text {th }}$ week postvaccination (Figure-4).

HI titers for NDV in sera of vaccinated chickens in different groups received the prepared mucosal vaccine increased and persisted till 7-9 weeks postvaccination except group 4 which received Gel 01 vaccine spray showed titers till 11 weeks. On the other hand, the ISA71 vaccinated group demonstrated high HI titers (with a peak of $8 \log 2$ at 8 weeks) persist till the 15 weeks postvaccination (Figure-5).

\section{Challenge trial \\ Protection \%}

After challenge with velogenic NDV genotype VIId NDV, the protection \% for groups received

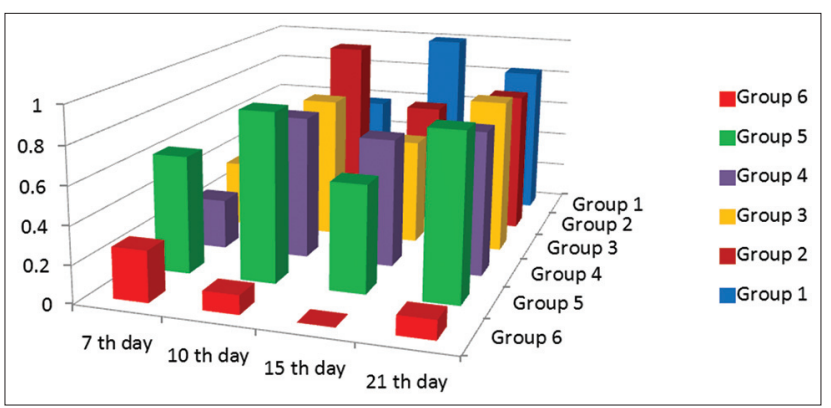

Figure-3: Phagocytic indices of vaccinated chickens at interval days as measured by phagocytic activity test.

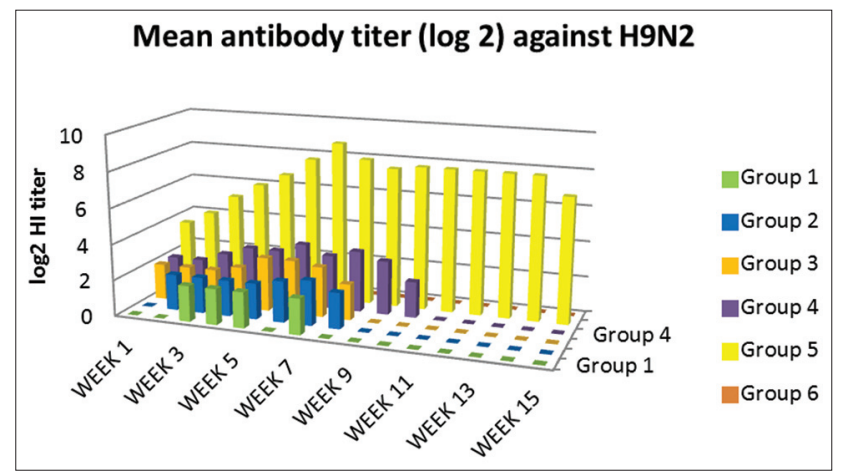

Figure-4: Hemagglutination inhibition means antibodies titer for H9N2 virus in sera of vaccinated chickens. 
IMS1313 vaccine was $40 \%$. Groups received the Gel 01 vaccine revealed $50 \%$ and $60 \%$ for intranasal and spray route; respectively. On the other hand, the chickens vaccinated with ISA71 vaccine demonstrated $100 \%$ protection (Figure-6). All chickens in positive control group were dead within $48 \mathrm{~h}$ after challenge.

\section{Shedding ratio after challenge with H9N2 virus}

The shedding in trachea after challenge with H9N2 for Groups 1-5 and positive control group at interval days measured by real-time RT-PCR. No shedding was detected in samples from Groups 4 and 5 (received Gel 01 and ISA71 vaccines, respectively) in all interval days. Groups 1 and 2 showed one log reduction in shedding compare to the positive control group, whereas Group 3 showed 4, 3, and 0 $\operatorname{logs}$ reduction at 2, 4 and 6 days post challenge, all groups showed no mortalities but showed flu-like signs (Table-1).

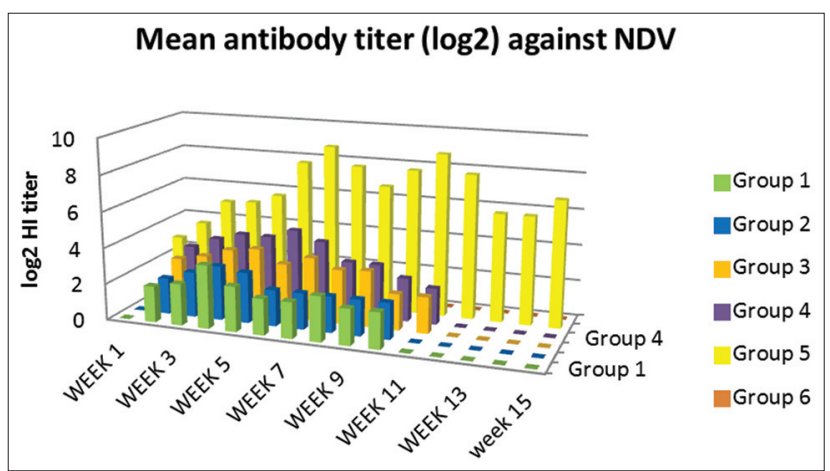

Figure-5: Hemagglutination inhibition means antibodies titer for Newcastle disease virus in sera of vaccinated chickens.

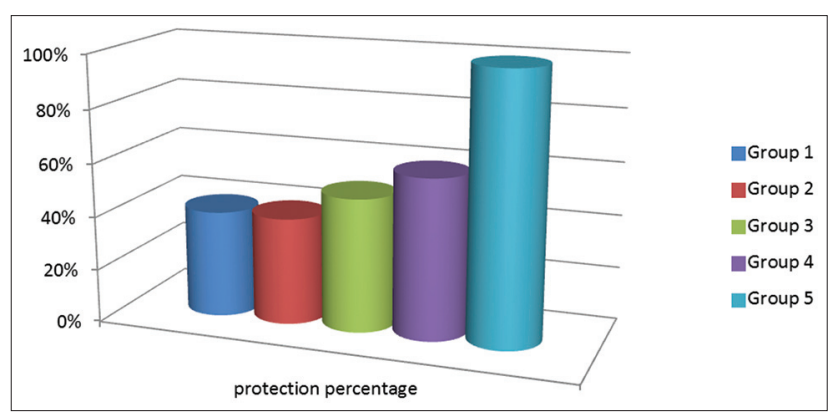

Figure-6: Protection \% against the velogenic Newcastle disease virus genotype VIId of different vaccinated and challenged chickens.

\section{Discussion}

Mucosal vaccination could be a very useful solution for efficient and protective vaccination of poultry flocks [37]. Development of mucosal delivered vaccines may induce superior protection against viruses that infect via mucosal surfaces by stimulating the cellular immunity. This study documents the immunoenhancing effects of montanide adjuvants on immune response of vaccinated birds. In this regard, we prepared two new mucosal bivalent vaccines for NDV and AIV H9N2 with nanoparticles and polymer adjuvants. The nanoparticles and polymers vaccine adjuvant can enhance the efficacy of avian mucosal vaccination against infectious diseases [38, 39]. We used qPCR to characterize the expression of IFN $\gamma$ and IL6 genes to provide insights into the role of innate immune response in protection against NDV and AIV H9N2 infection. The IMS1313 intranasal route induced response at 7 and 21 whereas spray route induced a high response at 7,15 and 21 days postvaccination. On the other hand, chicken group received Gel 01 via intranasal showed the highest response only at $7^{\text {th }}$ compared to those administrated via spray which has response at $15^{\text {th }}$ day postvaccination, these polymers have the ability to activate cellular immune response in the host [40] possibly, polymers may also interact and activate various tolllike receptors, thus involving several innate immune system players in immune response [41]. IFNs are important members of host innate arm of immunity to prevent virus infection by their antiviral effect and triggering apoptosis $[42,43]$. IL6 response of vaccinated groups of chicks showed waves of increasing and decreasing values differ from group to group. Chicken received Gel 01 via spray was the highest in their IL6 response. This increase in IL6 has a variety of functions, including the induction of acute phase proteins which impacts metabolic pathways [43], macrophage activation [44]. Phagocytic percentage and index measured at interval day's postvaccination showed gradual enhancement and the highest activity was in the $7^{\text {th }}$ and $21^{\text {th }}$ day for all groups. This increase as a result of enhancing in IL6 and IFN $\gamma$ as previously reported by $\mathrm{Hu}$ et al. [42], Katze et al. [43], Lienenluke and Christ [44]. H9N2 and NDV Abs were detected in low titers which were not increased

Table-1: The shedding ratio after challenge with H9N2.

\begin{tabular}{|c|c|c|c|c|c|c|c|c|c|}
\hline \multirow[t]{2}{*}{ Groups } & \multicolumn{3}{|c|}{2 days post challenge } & \multicolumn{3}{|c|}{4 days post challenge } & \multicolumn{3}{|c|}{6 days post challenge } \\
\hline & Result & Ct & $\begin{array}{c}\text { Shedding } \\
\text { amount }\left(\mathrm{EID}_{50}\right)\end{array}$ & Result & Ct & $\begin{array}{c}\text { Shedding } \\
\text { amount }\left(\text { EID }_{50}\right)\end{array}$ & Result & Ct & $\begin{array}{c}\text { Shedding } \\
\text { amount }\left(\text { EID }_{50}\right)\end{array}$ \\
\hline IMS/N & Negative & No Ct & - & Positive & 22.91 & $6.242 \times 10^{6}$ & Positive & 25.18 & $1.277 \times 10^{6}$ \\
\hline IMS/s & Positive & 29.01 & $8.778 \times 10^{4}$ & Positive & 24.24 & $2.463 \times 10^{6}$ & Positive & 26.77 & $4.202 \times 10^{5}$ \\
\hline GEL/N & Positive & 35.53 & $9.303 \times 10^{2}$ & Positive & 30.14 & $3.984 \times 10^{4}$ & Negative & No Ct & - \\
\hline GEL/S & Negative & No Ct & - & Negative & No Ct & - & Negative & No Ct & - \\
\hline ISA 71 & Negative & No Ct & - & Negative & No Ct & - & Negative & No Ct & - \\
\hline Control (+ve) & positive & 20.34 & $3.534 \times 10^{7}$ & positive & 21.9 & $1.256 \times 10^{7}$ & positive & 23.92 & $3.081 \times 10^{6}$ \\
\hline
\end{tabular}

$\mathrm{EID}_{50}=$ Embryo infective dose $50 \%$ 
above $5 \log 2$ in mucosaly vaccinated groups. These results were approved by others [45-47] who granted that aerosolized vaccines did enter the chicken respiratory tract either that's why the results showed low Abs titer and they suggested that the dose of influenza virus used was insufficient or a booster vaccination would be needed in order to induce detectable levels of $\mathrm{Ab}$, in the other hand the protection \% was determined after 3 weeks postvaccination in vaccinated groups, the protection \% of the polymer based adjuvant and ISA 71 were the most adjuvant formulations able to confer protection at high rate against infection with VVNDV and with no shedding in oropharyngeal swabs against infection with H9N2 AIV, these results confer to the Gel 01 formulation with spray route which is more efficient than the nanoparticles formulation and can enhance the efficacy of mass spray delivery of inactivated viral vaccines. This could be attributed to the mucoadhesive nature of the polymer compounds which give more contact time with respiratory tract mucosa hence give the chance to the innate immune response to take their role in protecting immune response [48-51]. It is known that that adaptive immune response initiated and regulated with previous non-specific innate immune response. There is marked elevation of IL6 gene expression early after vaccination which is very important for induction and regulation of innate immune response and directed the immune response to cellular immune response [38] Montanide gel 01 has been demonstrated to induce strong infiltration of monocytes and macrophages, so the inhanced phagocytosis of the antigen complex with the polymer increasing the activity of antigen-presenting cells, therefore, the innate immune response will trigger the adaptive immune system to induce a highly specific immune response $[48,52,53]$. The benefits anticipated from the use of adjuvant in inactivated vaccines concern both safety of the vaccine as the possible adverse reactions observed after delivery of live infectious vaccines could be lowered. Moreover, the risk of reversion to virulence that has already been observed in avian species could be also reduced $[54,55]$. The use of vaccines adjuvants expected to reduce the number of not responding birds and therefore reduce the possible reservoir for the infectious diseases [56].

\section{Conclusion}

Our work underlines the ability to use polymer adjuvant in mass vaccination for avian species against viral infections, opening doors to improvements of inactivated avian vaccines safety and efficacy.

\section{Authors' Contributions}

This work was a part of PhD thesis of HEM supervised by HAH and MSM. HME: Conducted the laboratory animal experimental work and drafted and revised the manuscript. MSM: Shared in design of the experimental work and follow up the practical part of the research. HAH: Sets the design, supervised the work, drafted and revised the manuscript. All authors have read and approved the final manuscript.

\section{Acknowledgment}

The authors would like to thank VSVRI, Cairo, Egypt for covering all the expenses of the experiment needed to conduct the work.

\section{Competing Interests}

The authors declare that they have no competing interests.

\section{References}

1. Naeem, K., Ullah, A., Manvell, R.J. and Alexander, D.J. (1999) Avian influenza A subtype H9N2 in poultry in Pakistan. Vet. Rec., 145: 560.

2. Bano, S., Naeem, K. and Malik, S.A. (2003) Evaluation of pathogenic potential of avian influenza virus serotype H9N2 in chickens. Avian Dis., 47: 817-822.

3. Capua, I. and Aalxander, D.J. (2004) Avian influenza: Recent developments. Avian Pathol., 33: 393-404.

4. Guo, Y.J., Krauss, S., Senne, D.A., Mo, I.P., Lo, K.S., Xiong, X.P., Orwood, M., Shortridge, K.F., Webster, R.G. and Guan, Y. (2000) Characterization of the pathogenicity of members of the newly established H9N2 influenza virus lineages in Asia. Virology, 267(2): 279-288.

5. Hussien, H.A. and Elazab, M. (2001) Evidence for the presence of H6 and H9 among broiler and layer breeders in Egypt. Proceedings XII International Congress World Veterinary Poultry Association, Cairo-Egypt. p227-235.

6. Arafa, A., Hagag, N., Erfan, A., Mady, W., El-Husseiny, M., Adel, A. and Nasef, S. (2012) Complete genome characterization of avian influenza virus subtype H9N2 from a commercial quail flock in Egypt. Virus Genes, 45: 283-294.

7. El-Zoghby, E.F., Arafa, A.S., Hassan, M.K., Aly, M.M., Selim, A., Kilany, W.H., Selim, U., Nasef, S., Aggor, M.G., Abdelwhab, E.M. and Hafez, H.M. (2012) Isolation of H9N2 avian influenza virus from bobwhite quail (Colinus virginianus) in Egypt. Arch. Virol., 157(6): 1167-1172.

8. Ekiert, D.C., Friesen, R.H., Bhabha, G., Kwaks, T., Jongeneelen, M., Yu, W., Ophorst, C., Cox, F., Korse, H.J., Brandenburg, B., Vogels, R., Brakenhoff, J.P., Kompier, R., Koldijk, M.H., Cornelissen, L.A., Poon, L.L., Peiris, M., Koudstaal, W., Wilson, I.A. and Goudsmit, J. (2011) A highly conserved neutralizing epitope on group 2 influenza a virus. Science, 333: 843-850.

9. Wei, T.C., Wei, P., Li, H.Q., He, C.W., Mo, M.L., Liu, L. and Chen, X. (2012) Molecular and genetic analysis of isolates of Newcastle disease virus of different poultry species origins during 1999-2012 in Guangxi, China. WVPAC, Nantes France.

10. Diel, D.G., da Silva, L.H.A., Liu, H., Wang, Z. and Miller, P.J. (2012) Genetic diversity of avian paramyxovirus Type 1: Proposal for a unified nomenclature and classification system of Newcastle disease virus genotypes. Infect. Genet. Evol., 12: 1770-1779.

11. Li, J., Hu, H., Yu, Q., Diel, D.G., Li, D.S. and Miller, P.J. (2012) Generation and characterization of a recombinant Newcastle disease virus expressing the red fluorescent protein for use in co-infection studies. J. Virol., 9: 227.

12. Huang, Y., Wan, H.Q., Liu, H.Q., Wu, Y.T. and Liu, X.F. (2004) Genomic sequence of an isolate of Newcastle disease virus isolated from an outbreak in geese: A novel six nucleotide insertion in the non-coding region of the nucleoprotein gene. Arch. Virol., 149(7): 1445-1457.

13. Radwan, M.M., Darwish, S.F., El-Sanousi, A.A. and Shalaby, M.A. (2013) Isolation and molecular characterization of Newcastle disease virus genotypes in Egypt between 
2011 and 2012. Virus Genes, 47(2): 311-316.

14. Amer, M.M., Wafaa, A. and El-Ghany, A. (2006) The effect of different Newcastle disease live vaccines and vaccination schedules on the immune response and performance of broiler chickens serologically positive to Mycoplasma. Beni-Suef Vet. Med. J., 16(1): 18-26.

15. Hussein, H.A., Emara, M.M., Samy, A.M. and Shalaby, M.A. (2000) Antigenic diversity of Newcastle disease virus isolated from 52 breeder and broiler flocks in Egypt. Egypt. $J$. Immune Vet., 2: 3-15.

16. Hassan, M.K., Afifi, M.M. and Ali, M.M. (2004) Genetic resistance of Egyptian chicken to infectious bursal disease and Newcastle diseases viruses. Trop. Anim. Health Prod., 36(1): 111-119.

17. Hussein, H.A., El-Sanousi, A.A., Youssif, A.A., Shalaby, M.A., Saber, M.S. and Reda, I.M. (2005) Sequence analysis of fusion and matrix protein genes of the velogenic viscerotropic Newcastle disease virus. Int. J. Virol., 1(1): 38 .

18. Hussein, H.A., Emara, M.M. and Rohaim, M.A. (2014) Molecular characterization of Newcastle disease virus genotype VIID in avian influenza H5N1 infected broiler flock in Egypt. Int. J. Virol., 10(1): 46.

19. Kang, S.M., Guo, L., Yao, Q., Skountzou, I. and Compans, R.W. (2004) Intranasal immunization with inactivated influenza virus enhances immune responses to coadministered simian-human immunodeficiency virus-like particle antigens. J. Virol., 78: 9624-9632.

20. Armerding, D., Rossiter, H., Ghazzouli, I. and Liehl, E. (1982) Evaluation of live and inactivated influenza A virus vaccines in a mouse model. J. Infect. Dis., 145: 320-330.

21. Sha, Z. and Compans, R.W. (2000) Induction of CD4 T-cellindependent immunoglobulin responses by inactivated influenza virus. J. Virol., 74: 4999-5005.

22. Takada, A., Matsushita, S., Ninomiya, A., Kawaoka, Y. and Kida, H. (2003) Intranasal immunization with formalin-inactivated virus vaccine induces a broad spectrum of heterosubtypic immunity against influenza A virus infection in mice. Vaccine, 21: 3212-3218.

23. Tamura, S.I., Asanuma, H., Ito, Y., Hirabayashi, Y., Suzuki, Y., Nagamine, T., Aizawa, C., Kurata, T. and Oya, A. (1992) Superior cross-protective effect of nasal vaccination to subcutaneous inoculation with influenza hemagglutinin vaccine. Eur. J. Immunol., 22: 477-481.

24. Tumpey, T.M., Renshaw, M., Clements, J.D. and Katz, J.M. (2001) Mucosal delivery of inactivated influenza vaccine induces B-cell-dependent heterosubtypic cross-protection against lethal influenza A H5N1 virus infection. J. Virol., 75: 5141-5150.

25. de Geusa, E.D., van Haarlema, D.A., Poetria, O.N., de Wit, J.J. and Vervelde, L. (2011) A lack of antibody formation against inactivated influenza virus after aerosol vaccination in presence or absence of adjuvantia. Vet. Immunol. Immunopathol., 143: 143-147.

26. de Wit, J.J., Swart, W.A. and Fabri, T.H. (2010) Efficacy of infectious bronchitis virus vaccinations in the field: Association between the alpha-IBV IgM response, protection and vaccine application parameters. Avian Pathol., 2: $123-131$.

27. Ley, D.H. (2003) Mycoplasmosis. In: Saif, Y.M., Barnes, H.J., Glission, J.R., Fadly, A.M., McDougald, L.R., Swayne, D.E., editors. Diseases of Poultry. Iowa State University Press, Ames, IA. p722-744.

28. Atmar, R.L., Keitel, W.A., Cate, T.R., Munoz, F.M., Ruben, F. and Couch, R.B. (2007) A dose-response evaluation of inactivated influenza vaccine given intranasally and intramuscularly to healthy young adults. Vaccine, 29: 5367-5373.

29. Worrall E.E., Sudarisman, Priadi A. (2009) Sialivac: An intranasal homologous inactivated split virus vaccine containing bacterial sialidase for the control of avian influenza in poultry. Vaccine, 31: 4161-4168.
30. Kapczynski, D.R., Afonso, C.L. and Miller, P.J. (2013) Immune responses of poultry to Newcastle disease virus. Dev. Comp. Immunol., 41: 447-453.

31. Akbari, O., DeKruyff, R.H. and Umetsu, D.T. (2001) Pulmonary dendritic cells producing IL-10 mediate tolerance induced by respiratory exposure to antigen. Nat. Immunol., 8: 725-731.

32. Hagenaars, N., Mastrobattista, E., Glansbeek, H., Heldens, J., van den Bosch, H., Schijns, V., Betbeder, D., Vromans, H. and Jiskoot, W. (2008) Head-to-head comparison of four nonadjuvanted inactivated cell culture-derived influenza vaccines: Effect of composition, spatial organization and immunization route on the immunogenicity in a murine challenge model. Vaccine, 26: 6555-6563.

33. Tseng, L.P., Chiou, C.J., Chen, C.C., Deng, M.C., Chung, T.W., Huang, Y.Y. and Liu, D.Z. (2009) Effect of lipopolysaccharide on intranasal administration of liposomal Newcastle disease virus vaccine to SPF chickens. Vet. Immunol. Immunopathol., 3-4: 285-289.

34. Riffault, S., Meyer, G., Deplanche, M., Dubuquoy, C., Durand, G., Soulestin, M., Castagné, N., Bernard, J., Bernardet, P., Dubosclard, V., Bernex, F., PetitCamurdan, A., Deville, S., Schwartz-Cornil, I. and Eléouët, J.F. (2010) A new subunit vaccine based on nucleoprotein nanoparticles confers partial clinical and virological protection in calves against bovine respiratory syncytial virus. Vaccine, 28: 3722-3734.

35. Deville, S., Arous, J.B., Bertrand, F., Borisov, V. and Dupuis, L. (2012) Efficacy of intranasal and spray delivery of adjuvanted live vaccine against infectious bronchitis virus in experimentally infected poultry. Procedia Vaccinol., 6: 85-92.

36. Branton, S.L., Roush, W.B., Lot, B.D., Evans, J.D., Dozier, W.A., Collier, S.D., Bearson, S.M., Bearson, B.L. and Pharr, G.T. (2005) A self propelled constant-speed spray vaccinator for commercial layer chicken. Avian Dis., 49: 147-151.

37. Jang, S.I., Lillehoj, H.S., Lee, S.H., Lee, K.W., Lillehoj, E.P., Bertrand, F., Dupuis, L. and Deville, S.(2011) Montanide ${ }^{\mathrm{TM}}$ IMS 1313 N VG PR nanoparticle adjuvant enhances antigen-specific immune responses to profilin following mucosal vaccination against Eimeria acervulina. Vet. Parasitol., 182: 163-170.

38. Corbanie, E.A., Matthijs, M.G., van Eck, J.H., Remon, J.P., Landman, W.J. and Vervaet, C. (2006) Deposition of differently sized airborne microspheres in the respiratory tract of chickens. Avian Pathol., 35: 475-485.

39. Shakya, A.K. and Nandakumar, K.S (2012) Applications of Polymeric Adjuvants in Studying Autoimmune Responses and Vaccination against Infectious Diseases. J R Society Interface 10: 20120536. Medical Inflammation Research, Department of Medical Biochemistry and Biophysics, Karolinska Institute, Stockholm, Sweden.

40. Deville, S. and Parker, R. (2008) Laval A. - Adjuvant formulation for influenza $\mathrm{H} 1 \mathrm{~N} 1$ and $\mathrm{H} 3 \mathrm{~N} 2$ pig vaccines. Montanide ${ }^{\mathrm{TM}}$ Gel safety and efficacy study. Proceedings of the Conference of Research of Workers in Animal Diseases, Chicago.

41. Purswell, J.L., Mayer, J.J., Evans, J.D., Branton, S.L. and Davis, J.D. (2012) Eye surface area and dosage rates for spray vaccination. Avian Dis., 54: 1310-1315.

42. Hu, Z., Hu, J., Hu, S., Liu, X., Wang, X., Zhu, J. and Liu, X. (2012) Strong innate immune response and cell death in chicken splenocytes infected with genotype VIId Newcastle disease virus. Virol. J., 9: 208.

43. Katze, M.G., He, Y. and Gale, M.Jr. (2002) Viruses and interferon: A fight for supremacy. Nat. Rev. Immunol., 2(9): 675-687.

44. Lienenluke, B. and Christ, B. (2007) Impact of interleukin-6 on the glucose metabolic capacity in rat liver. Histochem. Cell Biol., 128(4): 371-377.

45. Mizuguchi, M., Yamanouchi, H., Ichiyama, T. and 
Shiomi, M. (2007) Acute encephalopathy associated with influenza and other viral infections. Acta Neurol. Scand., 115(4): 45-56.

46. Ichinohe, T., Watanabe, I., Tao, E., Ito, S., Kawaguchi, A., Tamura, S., Takahashi, H., Sawa, H., Moriyama, M., Chiba, J., Komase, K., Suzuki, Y., Kurata, T., Sata, T. and Hasegawa, H. (2006) Protection against influenza virus infection by intranasal vaccine with surf clam microparticles (SMP) as an adjuvant. J. Med. Virol., 7: 954-963.

47. Joo, H.M., He, Y., Sundararajan, A., Huan, L. and Sangster, M.Y. (2010) Quantitative analysis of influenza virus-specific B cell memory generated by different routes of inactivated virus vaccination. Vaccine, 28(10): 2186-2194.

48. Rice-Ficht, A.C., Arenas-Gamboa, A.M., Kahl-McDonagh, M.M. and Ficht, T.A. (2009) Polymeric particles in vaccine delivery. Curr. Opin. Microbiol., 13(1): 106-112.

49. Thomasin, C., Corradin, G., Men, Y., Merkle, H.P. and Gander, B. (1996) Tetanus toxoid and synthetic malaria antigen containing poly(lactide)/poly(lactide-co-glycolide) microspheres: Importance of polymer degradation and antigen release for immune response. J. Controlled Release, 41(1-2): 131-145.

50. Karpala, A.J., Bingham, J., Schat, K.A., Chen, L.M., Donis, R.O., Lowenthal, J.W. and Bean, A.G. (2011) Highly pathogenic (H5N1) avian influenza induces an inflammatory $\mathrm{T}$ helper Type 1 cytokine response in the chicken. J. Interferon Cytokine Res., 31(4): 393-400.

51. Adams, S.C., Xing, Z., Li, J.L. and Cardona, C.J. (2009) Immune-related gene expression in response to H11N9 low pathogenic avian influenza virus infection in chicken and Pekin duck peripheral blood mononuclear cells. Mol. Immunol., 46(8): 1744-1749.

52. HogenEsch, H. (2002) Mechanisms of stimulation of the immune response by aluminum adjuvants. Vaccine, 20 Suppl 3: S34-S39.

53. Adams, J.R., Haughney, S.L. and Mallapragada, S.K. (2014) Effective polymer adjuvants for sustained delivery of protein subunit vaccines. Acta Biomater.14:104-114.

54. Susta, L., Hamel, K.R., Miller, P.J., Garcia, S.C., Brown, C.C., Pedersen, J.C., Gongora, V. and Afonso, C.L. (2012) Separate evolution of virulent Newcastle disease viruses from Mixico and Central American. J. Clin. Microbiol., 52: 1382-1390.

55. Fentie, T., Dadi, K., Kassa, T., Sahle, M. and Cattoli, G. (2014) Effect of vaccination on transmission characteristics of highly virulent Newcastle disease virus in experimentally infected chickens. Avian Pathol., 43(5): 420-426.

56. Damen, D., Fusaro, A., Sombo, M., Belaineh, R., Heidari, A., Kebede, A., Kidane, M. and Chaka, H. (2016) Characterization of Newcastle disease virus isolates obtained from outbreak cases in commercial chickens and wild pigeons in Ethiopia. Springerplus, 5: 476. 